\title{
Synthesis of $\boldsymbol{\gamma}$-Sanshool and Hydroxy- $\boldsymbol{\gamma}$-sanshool
}

\author{
Xuanshu Xia and Patrick H. Toy* \\ Department of Chemistry, The University of Hong Kong, Pokfulam Road, Hong Kong, P. R. of China \\ Fax +852 28571586; E-mail: phtoy@hku.hk \\ Received:
}

\begin{abstract}
Members of the family of polyunsaturated amide compounds known as the sanshools are found in various Zanthoxylum species such as Sichuan (or Szechuan) peppercorns (huajiao). $\gamma$ Sanshool and hydroxy- $\gamma$-sanshool have been synthesized from simple building blocks using an alkyne to $E, E$-1,3-diene isomerization reaction to stereoselectively install the $E, E$-2,4-diene group of the key synthetic intermediate $2 E, 4 E, 8 Z, 10 E, 12 E-$ tetradecapentaenoic acid, which in turn was converted into both $\gamma$ sanshool and hydroxy- $\gamma$-sanshool by reaction with the appropriate amines.
\end{abstract}

Key words: alkenes, alkynes, isomerization reactions, natural products, Wittig reactions

The sanshools are a family of polyunsaturated fatty acid amides found in various Zanthoxylum species that has recently attracted the interest of a broad cross-section of the scientific community (Figure 1). ${ }^{1} \quad$ For example, hydroxy- $\alpha$-sanshool (HAS) is responsible for the numbing/tingling sensation one experiences when eating Sichuan (or Szechuan) peppercorns (huajiao), ${ }^{2}$ and this finding has led to interest in understanding the details of its mechanism of action, ${ }^{3}$ and in developing various medicinal, ${ }^{4}$ agricultural, ${ }^{5}$ food, ${ }^{6}$ and cosmetic $^{7}$ applications for it. However, while HAS has been relatively widely studied, it is rather difficult to obtain in pure form. ${ }^{8}$ While much less is known regarding the other sanshools, ${ }^{9} \gamma$-sanshool (1) has been found to inhibit human acyl-CoA cholesterol acyltransferase-1, with an $\mathrm{IC}_{50}$ of $12 \mu \mathrm{M} .^{10}$ Thus, in order to increase the availability of the sanshools for wider study, we have initiated a program to synthesize them in stereochemically pure form, and have recently reported a synthesis of HAS that can be performed on a gram-scale. ${ }^{11-14}$ In this report, we describe the synthesis of $\mathbf{1}$ and hydroxyl- $\gamma$-sanshool (2) from a common carboxylic acid intermediate.

The synthesis of $\mathbf{1}$ has been previously described by two groups, and in both syntheses a Horner-Wadsworth-Emmons (HWE) reaction was used to construct the 2,4-diene group (Scheme 1). ${ }^{15,16}$ In the report published nearly 30 years ago by Crombie and Fisher, several synthetic strategies were described, but in the preferred route the $\mathrm{C}_{2}-\mathrm{C}_{3}$ double bond was formed from a HWE reaction. ${ }^{15 a}$ The authors did not discuss the stereoselectivity of this HWE reaction, but in the subsequent synthesis of $\mathbf{1}$ described by Igarashi et al., a similar HWE reaction used to form the $\mathrm{C}_{4}-\mathrm{C}_{5}$ double bond resulted in either a mixture of $E$ and $Z$ isomers, or only modest (40-56\%) yield of the desired product. ${ }^{16}$ Therefore, it seems that the synthesis by Crombie and Fisher possibly suffered from simi- lar issues. Furthermore, both syntheses utilized amide functionalized phosphonate reagents in the HWE reactions, which resulted in dienamide products. Thus, these two routes only resulted in the synthesis of $\mathbf{1}$, and do not involve an intermediate directly amenable to the synthesis of analogues of it in which the $N$-substituent varies, as it does in 2 . With these issues regarding this pervious work in mind, we felt that it would be useful to design a synthesis of $\mathbf{1}$ in which the issue of stereoisomers in the 2,4-diene group is eliminated, and that involves a carboxylic acid, which could also be used to generate not only $\mathbf{2}$, but a library of other amide analogues as well.

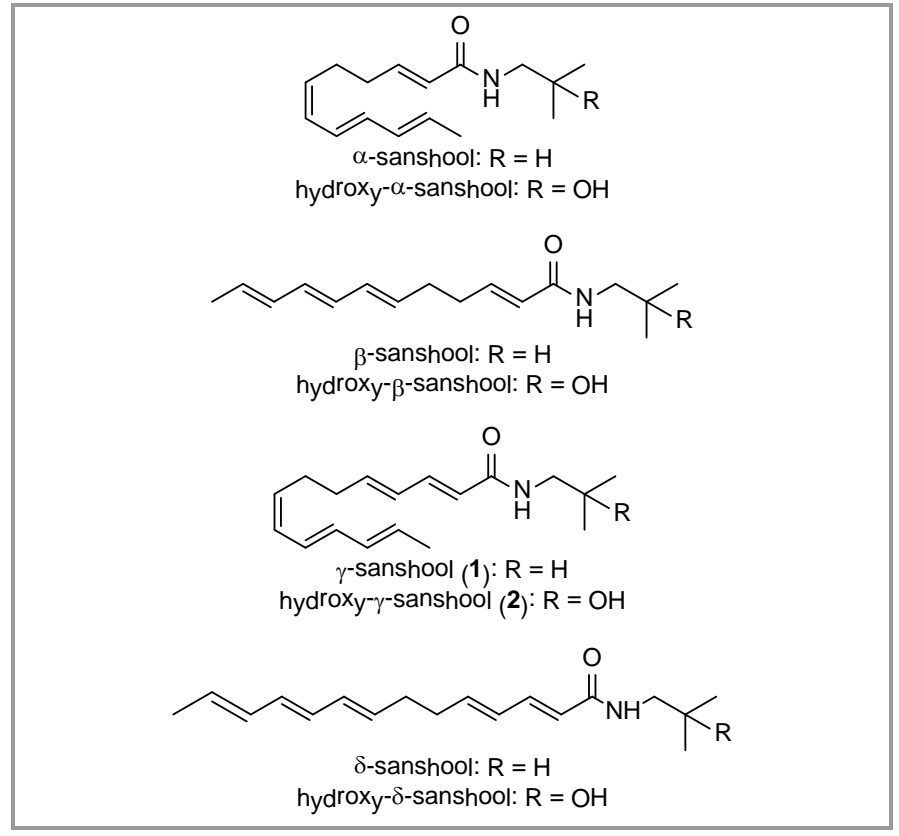

Figure 1 Sanshool compounds

Our retrosynthetic strategy for $\mathbf{1}$, and thus $\mathbf{2}$, is depicted in Scheme 2. As outlined above, carboxylic acid $\mathbf{3}$ was targeted as the key synthetic intermediate since it could conceivably be converted to a wide range of amides, and it might be prepared from alkynoate 4 using a stereoselective alkyne to $E, E-1,3-$ diene isomerization reaction, ${ }^{17,18}$ followed by saponification. The alkyne group of $\mathbf{4}$ could presumably be formed by a Corey-Fuchs reaction on aldehyde 5, using methyl chloroformate to trap the acetylide intermediate to install the ester moiety. Aldehyde 5 in turn might be generated by adjusting the oxidation state of ester $\mathbf{6}$, which itself might be synthesized via a Z-selective Wittig reaction between commercially available sorbaldehyde (7) and the phosphonium salt derived from $\mathbf{8}$. 


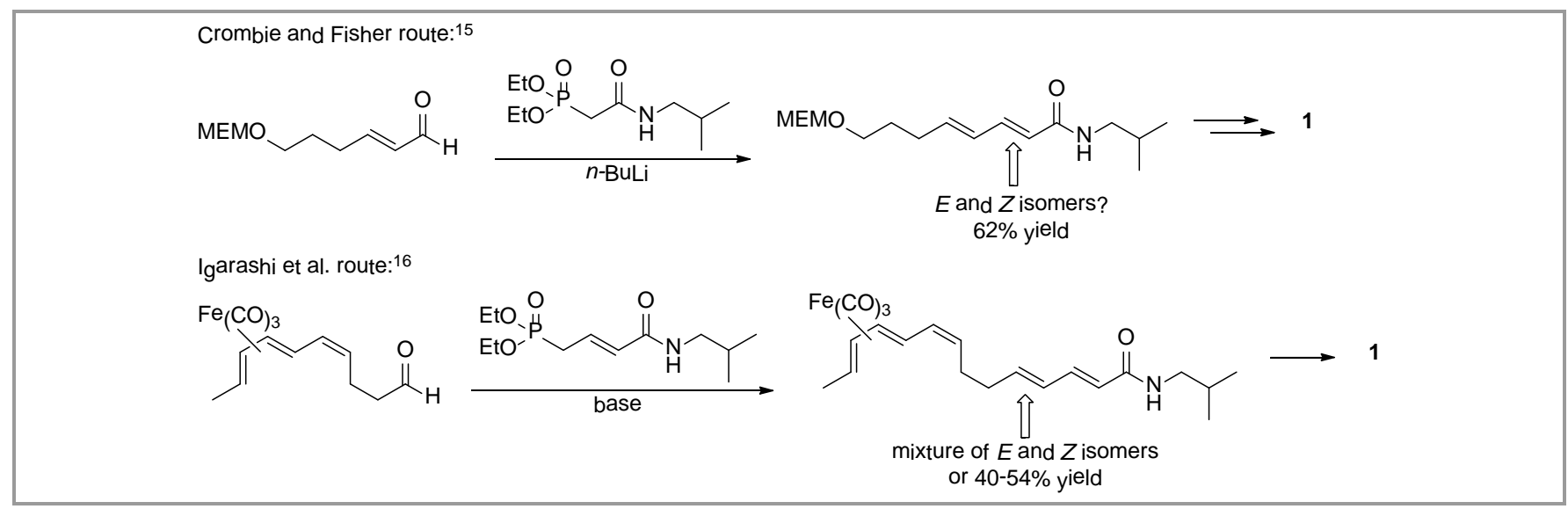

Scheme 1 Previous synthetic routes towards 1

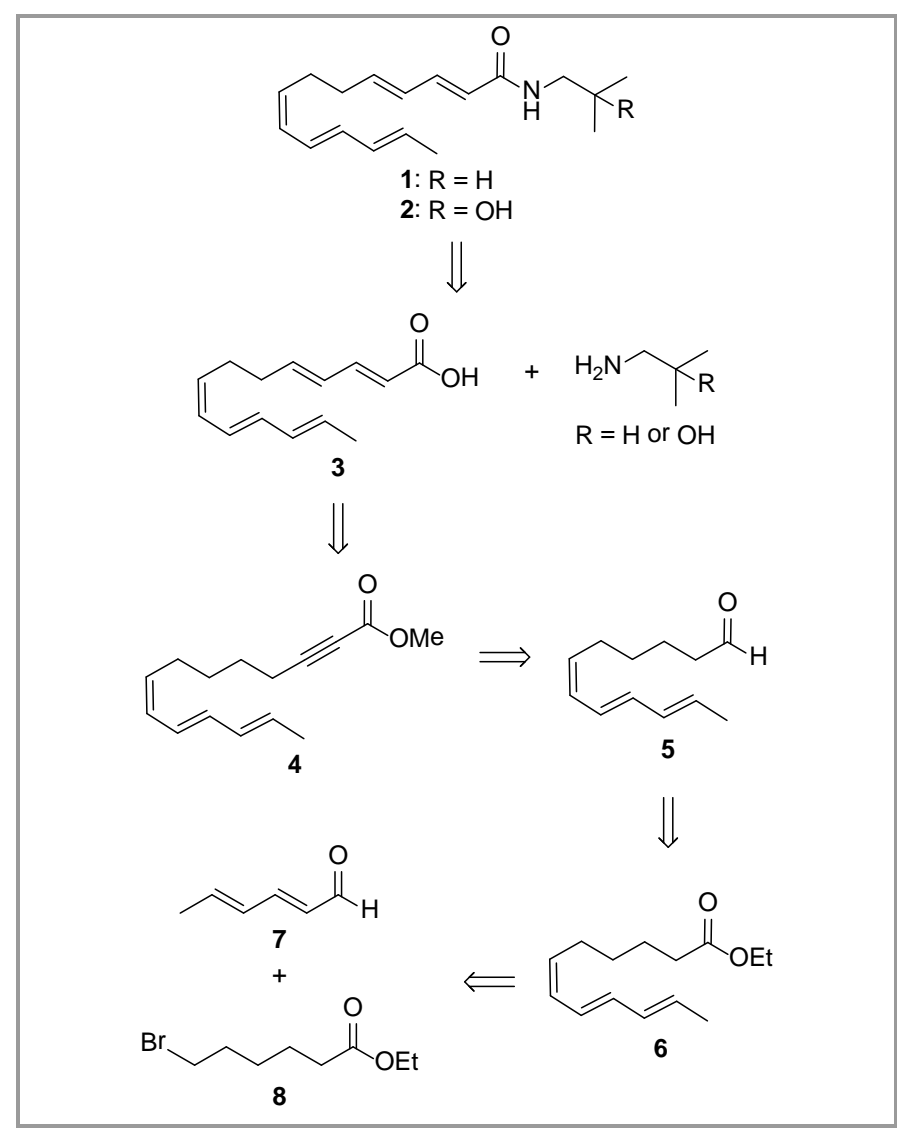

Scheme 2 Retrosynthetic analysis for $\mathbf{2}$ and $\mathbf{3}$

The successful implementation of our synthetic plan is presented in Scheme 3. ${ }^{19}$ Allkyl halide 8 was converted into the corresponding phosphonium salt $\mathbf{9}$ in high yield by reaction with $\mathrm{PPh}_{3}$, and this in turn was used in a Wittig reaction with aldehyde 7 using excess $\mathrm{Cs}_{2} \mathrm{CO}_{3}$ in warm $\mathrm{CH}_{2} \mathrm{Cl}_{2}$ to afford ester 6 as a mixture of $Z$ and $E$ stereoisomers (ca. 3:1 ratio). These were not separated, and the mixture was directly reduced using DIBAL-H to afford aldehyde $\mathbf{5}$ in high yield. Next, conversion of aldehyde $\mathbf{5}$ into alkynoate $\mathbf{4}$ was achieved in a 3-stage Corey-Fuchs procedure using methyl chlorofor- mate as the electrophile in good overall yield. Gratifyingly, the envisioned isomerization of $\mathbf{4}$ proceeded with high stereoselectivity in the presence of the combination of $\mathrm{PPh}_{3}$ and $\mathrm{PhOH}$ in warm PhMe to afford penultimate intermediate $\mathbf{1 0}$ in high yield. Saponification of $\mathbf{1 0}$ afforded solid carboxylic acid 3 , which could be recrystallized to a high level of stereochemical homogeneity using a combination of $\mathrm{CHCl}_{3}$ and hexane. Finally, amide formation using the appropriate amine afforded $\mathbf{1}^{20}$ and $\mathbf{2}^{21}$ in $28 \%$ and $29 \%$ overall yield, respectively, from $\mathbf{8}$. It should be noted that commercially available 7 is labeled as being "predominantly trans,trans", and is approximately a 5:1 mixture of stereoisomers according to ${ }^{1} \mathrm{H}$ NMR analysis. Thus, the relatively modest $63 \%$ yield for the saponification of $\mathbf{1 0}$ to form carboxylic acid $\mathbf{3}$ is quite respectable since the isomers formed due to the impurity of $\mathbf{7}$ and during the Wittig reaction are removed during this step.

In summary, we report a concise, stereoselective, and high yielding route for the synthesis of both 1 and 2 from simple and commercially available building blocks. Notably, carboxylic acid $\mathbf{3}$ can be recrystallized to purity, and its use as the immediate precursor to $\mathbf{1}$ and $\mathbf{2}$ allows for the synthesis of amide analogues of these natural products. We are currently investigating the application of our previously reported methods for using polymer-supported reagents and catalysts in Wittig $^{22}$ and alkyne isomerization ${ }^{23}$ reactions to the synthesis of $\mathbf{3}$, and it is hoped that this work will further facilitate the study of the sanshools by making them and their analogues more easily available.

Supporting Information for this article is available online at http://www.thieme-connect.com/ejournals/toc/synlett.

\section{Acknowledgement}

This research was supported financially by the University of Hong Kong and the Research Grants Council of the Hong Kong S. A. R., P. R. of China (Project No. HKU 705510P). 


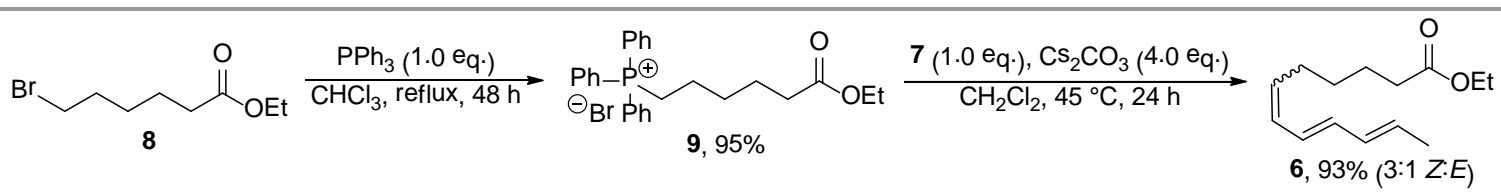
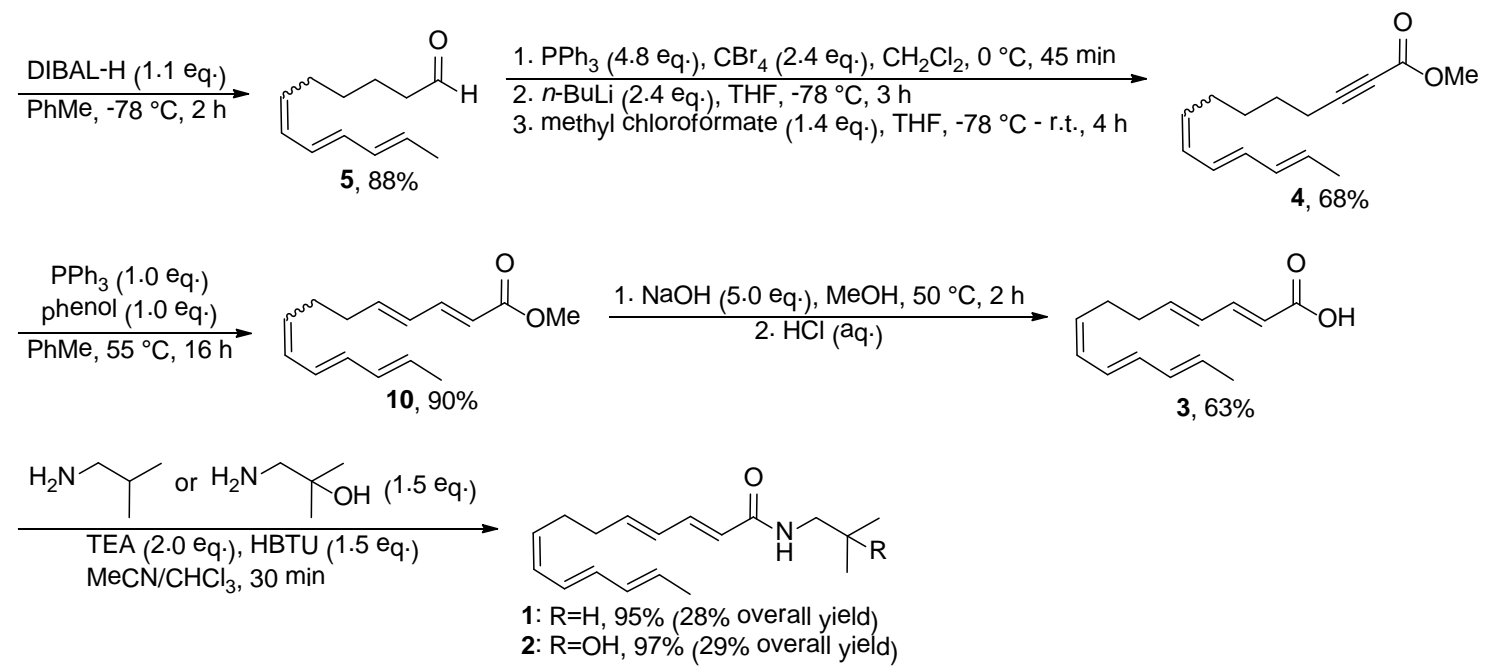

Scheme 3 Synthesis of 1 and 2

\section{References and Notes}

(1) (a) Crombie, L. J. Chem. Soc. 1955, 998. (b) Crombie, L.; Tayler, J. L. J. Chem. Soc. 1957, 2760. (c) Yasuda, I.; Takeya, K.; Itokawa, H. Chem. Pharm. Bull. 1981, 29, 1791. (d) Yasuda, I.; Takeya, K.; Itokawa, H. Phytochemistry 1982, 21, 1295. (e) Mizutani, K.; Fukunaga, Y.; Tanaka, O.; Takasugi, N.; Saruwatari, Y.-I; Fuwa, T.; Yamauchi, T.; Wang, J.; Jia, M.-R.; Li, F.-Y.; Ling, Y.-K. Chem. Pharm. Bull. 1988, 36, 2362. (f) Kashiwada, Y.; Ito, C.; Katagiri, H.; Mase, I.; Komatsu, K.; Namba, T.; Ikeshiro, Y. Phytochemistry 1997, 44, 1125. (g) Xiong, Q.; Shi, D.; Yamamoto, H.; Mizuno, M. Phytochemistry 1997, 46, 1123. (h) Chen, I.-S.; Chen, T.-L.; Lin, W.-Y.; Tsai, I.-L.; Chen. Y.-C. Phytochemistry 1999, 52, 357. (i) Iseli, V.; Potterat, O.; Hagmann, L.; Egli, J.; Hamburger, M. Pharmazie 2007, 62, 396. (j) Jang, K. H.; Chang, Y. H.; Kim. D.-D.; Oh, K.-B.; Oh, U.; Shin, J. Arch. Pharm. Res. 2008, 31, 569. (k) Yang, X. J. Agric. Food. Chem. 2008, 56, 1689. (l) Machmudah, S.; Izumi, T.; Sasaki, M.; Goto, M. Sep. Purif. Technol. 2009, 68, 159. (m) Huang, S.; Zhao, L.; Zhou, X. L.; Ying, M.; Wang, C. J.; Weng, J. Chin. Chem. Lett. 2012, 23, 1247.

(2) (a) Bryant, B. P.; Mezine, I. Brain Res. 1999, 842, 452. (b) Sugai, E.; Morimitsu, Y.; Iwasaki, Y.; Morita, A.; Watanabe, T.; Kubota, K. Biosci. Biotechnol. Biochem. 2005, 69, 1951.

(3) (a) Koo, J. Y.; Jang, Y.; Cho, H.; Lee, C.-H.; Jang, K. H.; Chang, Y. H.; Shin, J.; Oh, U. Eur. J. Neurosci. 2007, 26, 1139-1147. (b) Bautista, D. M.; Sigal, Y. M.; Milstein, A. D.; Garrison, J. L.; Zorn, J. A.; Tsuruda, P. R.; Nicoll, R. A.; Julius, D. Nature Neurosci. 2008, 11, 772-779. (c) Riera, C. E.; Menozzi-Smarrito, C.; Affolter, M.; Michlig, S.; Munari, C.; Robert, F.; Vogel, H.; Simon, S. A.; le Coutre, J. Br. J. Pharmacol. 2009, 157, 1398-1409. (d) Lennertz, R. C.; Tsunozaki, M.; Bautista, D. M.; Stucky, C. L. J. Neurosci. 2010, 30, 4353. (e) Tsunozaki, M.; Lennertz, R. C.; Vilceanu, D.; Katta, S.; Stucky, C. L.; Bautista, D. M. J. Physiol. 2013, 591, 3325. (f) Bader, M.; Stark, T. M.; Dawid, C.; Lösch, S.; Hofmann, T. J. Agric. Food Chem. 2014, 62, 2479.

(4) (a) Baraldi, P. G.; Preti, D.; Materazzi, S.; Geppetti, P. J. Med. Chem. 2010, 53, 5085. (b) Mathie, A. J. Pharm. Pharmacol.
2010, 62, 1089. (c) Es-Salah-Lamoureux, Z.; Steele, D. F.; Fedida, D. Trends Pharmacol. Sci. 2010, 31, 587.

(5) Tang, X.; Zhou, X.; Wu, J.; Li, J.; Bai, L. Pestic. Biochem. Physiol. 2014, 110, 44.

(6) Starkenmann, C.; Cayeux, I.; Birkbeck, A. A. Chimia 2011, 65, 407.

(7) Artaria, C.; Maramaldi, G.; Bonfigli, A.; Rigano, L.; Appendino, G. Int. J. Cosmetic Sci. 2011, 33, 328.

(8) According to Bautista et al., ${ }^{3 \mathrm{~b}} 50 \mathrm{~g}$ of dried seeds from Zanthoxylum piperitum afforded $55.2 \mathrm{mg}$ of crude HAS after preparative HPLC. Repetitive chromatographic separation was required to further purify $\mathbf{1}$ to homogeneity.

(9) (a) Navarrete, A.; Hong, E. Planta Med. 1996, 62, 250. (b) Dossou, K. S. S.; Devkota, K. P.; Morton, C.; Egan, J. M.; Lu, G.; Beutler, J. A.; Moaddel, R. J. Nat. Prod. 2013, 76, 2060.

(10) Park, Y.-D.; Lee, W. S.; An, S.; Jeong, T. S. Biol. Pharm. Bull. 2007, 30, 205.

(11) Wu, B.; Li, K.; Toy, P. H. Synlett 2012, 23, 2564.

(12) For the synthesis of $\mathrm{f} \alpha$-sanshool, see: Sonnet, P. E. J. Org. Chem. 1969, 34, 1147.

(13) For another synthesis and HAS and hydroxy- $\beta$-sanshool, see: Igarashi, Y.; Aoki, K.; Nishimura, H.; Morishita, I.; Usui, K. Chem. Pharm. Bull. 2012, 60, 1088.

(14) For the synthesis and evaluation of simplified analogues of HAS, see: Menozzi-Smarrito, C.; Riera, C. E.; Munari, C.; le Coutre, J.; Robert, F. J. Agric. Food Chem. 2009, 57, 1982.

(15) (a) Crombie, L.; Fisher, D. Tetrahedron Lett. 1985, 26, 2477. (b) Crombie, L.; Fisher, D. Tetrahedron Lett. 1985, 26, 2481.

(16) Aoki, K.; Igarashi, Y.; Nishimura, H.; Morishita, I.; Usui, K. Tetrahedron Lett. 2012, 53, 6000.

(17) (a) Trost, B. M.; Kazmaier, U. J. Am. Chem. Soc. 1992, 114, 7933. (b) Guo, C.; Lu, X. J. Chem. Soc., Chem. Commun. 1993, 394. (c) Rychnovsky, S. D.; Kim, J. J. Org. Chem. 1994, 59), 2659. (d) Strunz, G. M.; Finlay, H. J. Can. J. Chem. 1996, 74, 419. (e) Kwong, C. K.-W.; Fu, M. Y.; Lam, C. S.-L.; Toy, P. H. Synthesis 2008, 2307. (f) Fu, M. Y.; Guo, J.; Toy, P. H. Synlett 2011, 989.

(18) For a recent example of the application of this reaciton in complex natural product synthesis, see: Wang, Y.; O’Doherty, G. A. J. Am. Chem. Soc. 2013, 135, 9334. 
(19) See Supporting Information for details.

(20) Characterization data for $1:^{1 \mathrm{c} 1} \mathrm{H}-\mathrm{NMR}\left(400 \mathrm{MHz}, \mathrm{CDCl}_{3}\right) \delta$ 0.92 (d, $6 \mathrm{H}, J=6.5 \mathrm{~Hz}), 1.78$ (d, 3H, $J=6.5 \mathrm{~Hz}), 1.81$ (q, $1 \mathrm{H}, J=6.5 \mathrm{~Hz}), 2.25(\mathrm{t}, 2 \mathrm{H}, J=6.7 \mathrm{~Hz}), 2.30(\mathrm{t}, 2 \mathrm{H}, J=6.7$ $\mathrm{Hz}), 3.15(\mathrm{t}, 2 \mathrm{H}, J=6.5 \mathrm{~Hz}), 5.36\left(\mathrm{dt}, 1 \mathrm{H}, J_{1}=9.7 \mathrm{~Hz}, J_{2}=\right.$ $7.4 \mathrm{~Hz}), 5.72\left(\mathrm{dt}, 1 \mathrm{H}, J_{1}=14.0 \mathrm{~Hz}, J_{2}=7.0 \mathrm{~Hz}\right), 5.81(\mathrm{~d}, 1 \mathrm{H}$, $J=15.2 \mathrm{~Hz}$ ), 5.85 (s, $1 \mathrm{H}), 5.99-6.20$ (m, 5H), 6.29-6.33 (m, $1 \mathrm{H}), 7.17$ (dd, $\left.1 \mathrm{H}, J_{1}=14.6 \mathrm{~Hz}, J_{2}=10.7 \mathrm{~Hz}\right) ;{ }^{13} \mathrm{C}-\mathrm{NMR}$ $\left(100 \mathrm{MHz} \mathrm{CDCl}_{3}\right) \delta 18.4,20.2,27.2,28.7,33.0,47.0,122.4$, 125.4, 128.9, 129.5, 130.0, 130.1, 132.0, 133.4, 141.0, 141.8, 166.5; MS for $\mathrm{C}_{18} \mathrm{H}_{27} \mathrm{NO}$ : calc 273.2, found 273.2.

(21) Characterization data for $2:{ }^{1 \mathrm{e}} \mathrm{H}-\mathrm{NMR}\left(400 \mathrm{MHz}, \mathrm{CDCl}_{3}\right) \delta$ 1.22 (s, 6H), 1.78 (d, 3H, $J=6.7 \mathrm{~Hz}), 2.25$ (t, 2H, $J=6.7$ $\mathrm{Hz}), 2.30(\mathrm{t}, 2 \mathrm{H}, J=6.7 \mathrm{~Hz}), 3.33(\mathrm{~d}, 2 \mathrm{H}, J=5.9 \mathrm{~Hz}), 5.35$ (dt, $\left.1 \mathrm{H}, J_{1}=10.1 \mathrm{~Hz}, J_{2}=7.5 \mathrm{~Hz}\right), 5.72\left(\mathrm{dt}, 1 \mathrm{H}, J_{1}=14.0 \mathrm{~Hz}\right.$, $\left.J_{2}=6.8 \mathrm{~Hz}\right), 5.84(\mathrm{~d}, 1 \mathrm{H}, J=15.0 \mathrm{~Hz}), 5.99-6.02(\mathrm{~m}, 5 \mathrm{H})$, 6.29-6.36 (m, 1H), 7.19 (dd, $1 \mathrm{H}, J_{1}=15.0 \mathrm{~Hz}, J_{2}=10.4 \mathrm{~Hz}$ ); ${ }^{13} \mathrm{C}-\mathrm{NMR}\left(100 \mathrm{MHz}, \mathrm{CDCl}_{3}\right) \delta 18.4,27.1,27.3,33.0,50.6$, 71.0, 121.9, 125.4, 128.8, 129.6, 130.0, 130.1, 131.9, 133.5, 141.6, 142.4, 167.7; MS for $\mathrm{C}_{18} \mathrm{H}_{27} \mathrm{NO}_{2}$ : calc 289.2, found 289.2 .

(22) (a) Leung, P. S.-W.; Teng, Y.; Toy, P. H. Synlett 2010, 19972001. (b) Leung, P. S.-W.; Teng, Y.; Toy, P. H. Org. Lett. 2010, 12, 4996-4999. (c) Teng, Y.; Lu, J.; Toy, P. H. Chem. Asian J. 2012, 7, 351-359.

(23) Kwong, C. K.-W.; Fu, M. Y.; Law, H. C.-H.; Toy, P. H. Synlett 2010, 2617. 
Graphical abstract

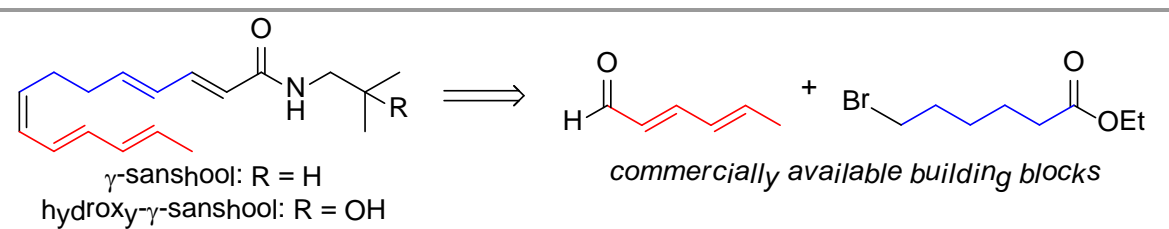

hydroxy- $\gamma$-sanshool: $\mathrm{R}=\mathrm{OH}$ 